\section{Potential of bio-drying applied to exhausted grape marc}

\author{
Elena Cristina Rada, Marco Ragazzi \\ Department of Civil and Environmental \\ Engineering, University of Trento, Italy
}

\section{Abstract}

In the present work, experimentation was carried out to study the behavior of exhausted grape marc during the bio-drying process. This process was chosen as an alternative to the typical grape marc thermal drying approach. The aim was to reduce the moisture level thanks to the biological exothermal reactions, and to increase the energy content in the biodried grape marc. The target was the generation of a product interesting for energy options. For the development of the research, a biological pilot reactor and a respirometric apparatus were used. Results demonstrated that bio-drying can decrease the water content saving the original energy content. The final material could be assumed like a solid recovered fuel, class 5:1:1 with a very low potential rate of microbial self-heating.

\section{Introduction}

The wine industry produces every years in the world about 270 millions of hectoliters of wine, of which about the half in European Union (EU), and in particular in Spain, Italy and France; Italy and France compete each year for being the main world wine producer.

The central wine regulations in the $\mathrm{EU}$ is entitled Council Regulation on the common organization of the market in wine, of 29 April 2008 and was supplemented by Council Regulation (EC) No 491/2009 of 25 May 2009 amending Regulation (EC) No 1234/2007 that establish a common organization of agricultural markets and specific provisions for certain agricultural products. From the regulatory point of view the wastewater generated from the sector must be treated according to the principals available for the management of this kind of discharge.

The Province of Trento, Italy, where the present research was performed, generates about 800,000 hectoliters of wine per year. To produce one liter of wine about $1.3 \mathrm{~kg}$ of grape are utilized, and about the $20 \%$ of this grape represents a waste of the wine industry. ${ }^{1}$ The exhausted grape marc (GM) or spent GM, is the material that results after fermentation and distillation of the grapes in the wine companies and has a high organic content. ${ }^{2}$ This exhausted grape marc contains generally about $72 \%$ skins, $20-22 \%$ seeds and $7-8 \%$ stalks. ${ }^{3}$ The exhausted GM used for the experimentation is presented in Figure 1.

Grape marc has traditionally been used to produce pomace brandy (such as grappa), grape-seed oil, polymers and seldom as supplement in animal feed. ${ }^{4-6}$ Today, it is mostly used as fertilizer or for producing renewable energy. However, in 2011, Devesa-Rey presented a study regarding the possibility of valorization of winery waste $v s$. the costs of not recycling. ${ }^{2}$ The valorization scenarios didn't take into account the potential role of GM bio-drying. This lack confirms the originality of the contents of the present paper, where an alternative technique to treat exhausted grape marc is presented for energy purposes. The chosen process is an aerobic biological-mechanical treatment: the bio-drying one. The aim of this process is the exploitation of the exothermic reactions for the evaporation of the highest part of the water present in the treated material with the lowest conversion of organic carbon. The experimental results of a pilot scale bio-drying process applied to exhausted grape marc are presented and discussed in this paper. An important advantage of the use of bio-drying is that the final product, like solid recovered fuel (SRF), is considered biomass opening to the incentives market for renewable energy. An important parameter for the SRF characterization is the potential rate of microbial self heating. This rate can be determined by the real dynamic respiration index (RDRI=average value of the respiration indexes representing $24 \mathrm{~h}$ showing the highest aerobic microactivity). Until 2010 in Italy this parameter has been requested only for the stabilized organic fraction and not for fuels. ${ }^{7}$ With the transposition of the technical norm CEN/TR 15590 in the decree 205/2010, this RDRI parameter became a key parameter for SRF.

Bio-drying of exhausted grape marc can be an alternative to thermal drying generally performed in the sector by an integrated plant of thermal-pre-treatment and combustion. This integration has the disadvantage of requiring a centralization of the pre-treatment. Grape marc bio-drying could open to a decentralized pre-treatment of this organic substrate before a centralized combustion.

\section{Materials and Methods}

In order to develop the bio-drying process, a bioreactor of $1 \mathrm{~m}^{3}$ was used at University of Trento. ${ }^{9,10}$ When performing a run, the adopted reactor (Figure 2) was placed on an electronic balance for monitoring the mass loss during the bio-drying process. The process air was
Correspondence: Elena Cristina Rada, Department of Civil and Environmental Engineering, University of Trento, via Mesiano 77, I-38050 Trento, Italy.

Fax: +39.0461.282613 - +39.0461.282672.

E-mail: elena.rada@ing.unitn.it

Key words: bio-drying, exhausted grape marc, solid recovered fuel.

Contributions: the authors contributed equally.

Received for publication: 11 March 2012.

Accepted for publication: 20 June 2012.

This work is licensed under a Creative Commons Attribution 3.0 License (by-nc 3.0).

(C)Copyright E.C. Rada and M. Ragazzi, 2012

Licensee PAGEPress, Italy

Wine Studies 2012; 2:e2

doi:10.4081/ws.2012.e2

sent into the reactor through a steel diffuser, placed at the bottom. The air crossed upward the matter from the lower part, activating the biological reactions and went out of the biological reactor from the upper part, extracting a part of the water content of the material. The leachate was discharged continuously in order to avoid alterations of the dynamics of weight loss. For monitoring the temperature during the bio-drying process, four temperature probes were placed inside the reactor, one at the air outlet/inlet and two at intermediate levels. All these equipments were connected to a data acquisition system developed for a good management of the process.

A bio-chemical model based on an energy and mass balance was used for a correct interpretation of the experimental data reported in this paper. ${ }^{9}$ In particular the model reconstructs the composition of the bio-dried material through a process balance taking into account the mass, the biochemical reactions stoichiometry and the available energy, resulting at the end a determined mathematical system that has as input the quantity of water, carbon, hydrogen, oxygen and nitrogen contained in the initial mass of exhausted GM and as output the amount of water, carbon, hydrogen, oxygen and nitrogen consumed/removed during the bio-drying process. The model also describes the dynamics of the calorific value during the bio-drying process. Additionally the model gives the dynamics of the following parameters of interest: i. internal energy consumption (overall available lower heating value, LHV); ii. volatile solids reduction (assessed from an energy balance); iii. net moisture extraction (taking into account the role of hydrogen); iv. highest theoretical $\mathrm{NH}_{3}$ emission factor (supposing that $100 \%$ of nitro- 
gen is converted into ammonia).

The aeration criteria were adopted in order to optimize the temperature of the biological bio-drying process taking into account the microbial activity needs: the highest value was limited at $65^{\circ} \mathrm{C}$.

For the experimental run, that lasted 30 days, about $96 \mathrm{~kg}$ of exhausted grape marc were used. The height of the material in the bio-drying pilot plant was about $22 \mathrm{~cm}$. The moisture content of the exhausted grape marc and of the bio-dried one was determined using a stove at $105^{\circ} \mathrm{C}$ for $24 \mathrm{~h}$.

For the volatile and total solids (VS and TS) content and also for the elemental composition a provincial laboratory was used. Carbon, hydrogen, oxygen, sulfur and nitrogen were determined taking into account the UNI 99036:1992 norm, and for the Copper content the EPA 3050B and EPA 6010C were used. For the chlorine and mercury content needed for discussing the role of bio-drying towards SRF generation, the determination was made taking into account the ISTISAN'99 and EPA 50505 or/and EPA 9056A.

Generally the lasting of the bio-drying runs is about 2 weeks, when adopted for municipal solid waste. ${ }^{11}$ For a better understanding of the potential of the bio-drying process applied to exhausted grape marc: i. lasting was doubled; ii. data from respirometry tests regarding the oxygen consumption of the exhausted grape marc before and after the bio-drying process, were generated; iii. chemical oxygen demand (COD) was determined in specific cases.

The dynamic respirometer AIR NL (respirometric index analyzer with not limiting oxygen) developed by the University of Trento was used in order to have data about the oxygen uptake rate of the organic matrix. ${ }^{12}$ Inside of this instrument a controlled aeration in no limiting oxygen conditions is made. The respirometric index (IR=potential rate of microbial self heating) calculation starts from the decrease of the oxygen concentration curve in the interstitial air of the waste sample, due to bacterial activity. This rate can be determined by the real dynamic respiration

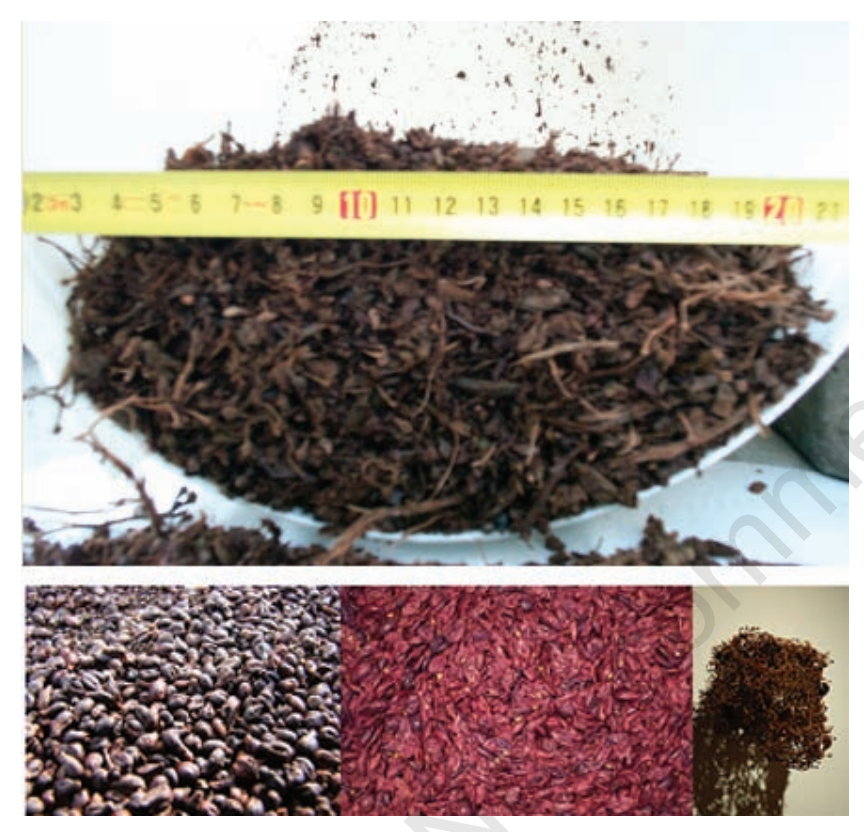

Figure 1. Exhausted grape marc: seeds, skins and stalks.

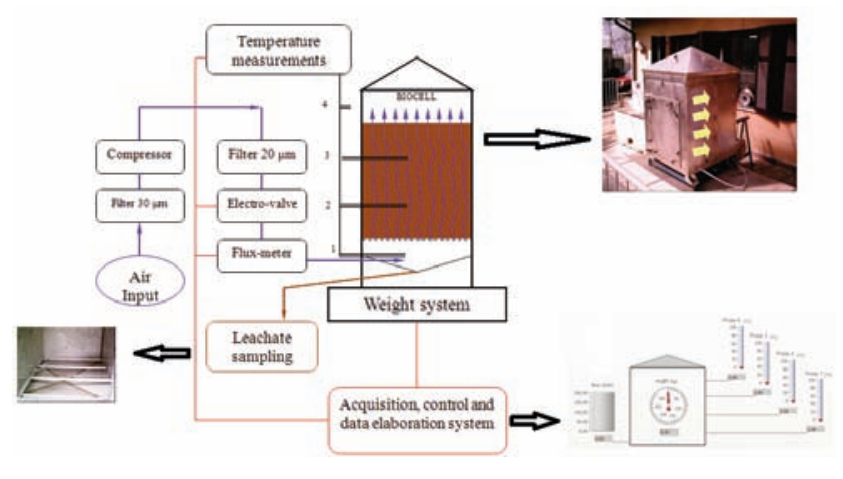

Figure 2. Biological reactor.

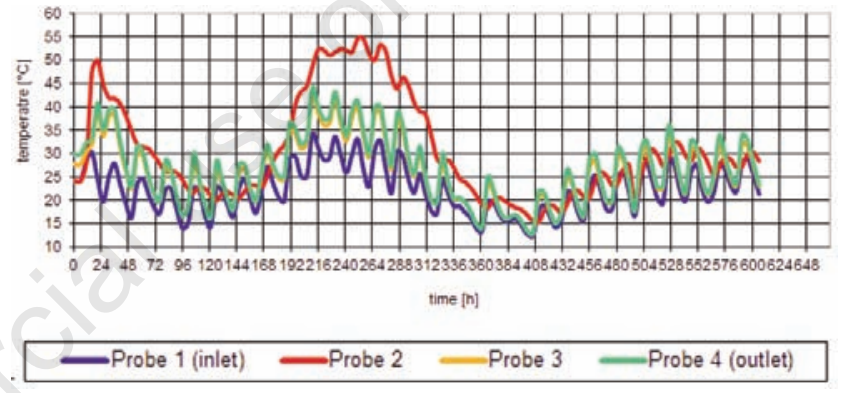

Figure 3. Temperature dynamics during the bio-drying run.

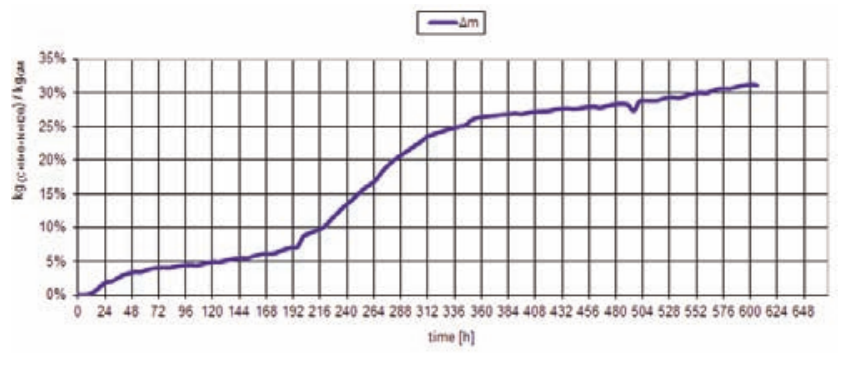

Figure 4. Mass loss dynamics during the bio-drying run.

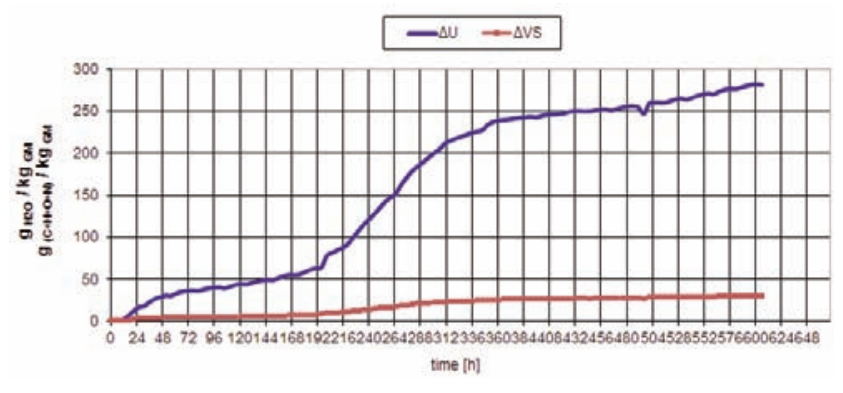

Figure 5. Moisture and volatile solids dynamics ( $\Delta \mathrm{U}$ and $\Delta \mathrm{VS})$ during the bio-drying run. 
index (IR24=RDRI=average value of the respiration indexes representing $24 \mathrm{~h}$ showing the highest aerobic microactivity).

\section{Results}

In Table 1 data regarding VS and TS of the exhausted grape marc before bio-drying are presented. Table 2, instead, presents data regarding the ratios VS/TS and TS/GM, the moisture of the initial exhausted GM and the moisture of the bio-dried GM. These values are similar with the ones available in the literature. $^{13}$ The chlorine and mercury contents were measured: the values for the used exhausted GM sample resulted $\mathrm{Cl}<50 \mathrm{mg} / \mathrm{kg}$ and $\mathrm{Hg}=0.0022 \mathrm{mg} / \mathrm{kg}$ respectively.

Using the cited bio-chemical model the dynamics of the main parameters for characterizing the exhausted grape marc bio-drying were developed. ${ }^{9}$ Data concerning temperature dynamic during the bio-drying run are reported in Figure 3.

Mass loss during the bio-drying run is presented in Figure 4. The mass loss depended strongly on the quantity of putrescible materials present in the input material.

The VS and net water loss were assessed by the quoted model and are presented in Figure $5 .{ }^{9}$ The water loss $(\Delta \mathrm{U})$ was assessed taking into account the role of hydrogen during the bio-oxidation that characterizes the bio-drying process. VS consumption was minimized thanks to the avoidance of water addition. By this way the presence of carbon was maximized, giving interesting results in term of specific LHV increase as it can be seen in Figure 6.

The emission factors of ammonia were assessed by modeling and referred to a theoretical case where all the nitrogen present in the treated material is converted into ammonia and emitted through the process air. ${ }^{9}$ The results are presented in Figure 7.
For a better understanding of the exhausted grape marc use, COD values were generated. To this concern, a part of a sample was dried at $105^{\circ} \mathrm{C}$ for $24 \mathrm{~h}$, shredded and homogenized. The COD of the dried exhausted GM resulted $1961 \mathrm{~g} 02 / \mathrm{kg}_{\mathrm{DM}}$. Another part of the sample was washed and centrifuged at $4000 \mathrm{rpm}$ for $5 \mathrm{~min}$. The COD of the washed exhausted GM resulted $1624 \mathrm{~g}_{02} / \mathrm{kg}_{\mathrm{DM}}$. The COD of the liquid phase was determined too. Its value was $27.8 \mathrm{~g}_{02} / \mathrm{L}$. The potential rates of microbial self-heating of initial and bio-dried exhausted GM were also determined. The obtained results $\left(\mathrm{IR}_{24}\right)$ were 750 and $500 \mathrm{mg}_{02} \mathrm{~kg}^{-1} \mathrm{TS} \mathrm{h}^{-1}$ respectively.

\section{Discussion}

Grape marc, even if exhausted showed a residual activity that supported a quick increase of temperature. Indeed, this phenomenum is confirmed by the fact that at the beginning the temperature in the core of the exhausted grape marc was about $24^{\circ} \mathrm{C}$, after only one hour increased and after half day arrived to about $52^{\circ} \mathrm{C}$.

Even if the lasting of the process was doubled the results after the first two weeks were suitable instead the results for the last 2 weeks were less important, the process slowed down significantly: i. the temperatures in the last 2 weeks didn't overcome $40^{\circ} \mathrm{C}$; on the contrary in the first 2 weeks they reached $55^{\circ} \mathrm{C}$ (Figure 3 ); ii. the mass, VS and water losses in the last 2 weeks didn't exceed $9 \%, 9 \mathrm{~g}_{(\mathrm{C}+\mathrm{H}+\mathrm{O}+\mathrm{N})} / \mathrm{kgGM}$ and $61 \mathrm{~g}_{\mathrm{H} 2 \mathrm{O}} / \mathrm{kg}_{\mathrm{GM}}$ respectively; on the contrary in the first 2 weeks they arrived to about $23 \%$, $23 \mathrm{~g}_{(\mathrm{C}+\mathrm{H}+0+\mathrm{N})} / \mathrm{kgGM}$ and $221 \mathrm{~g}_{\mathrm{H} 20} / \mathrm{kg}_{\mathrm{GM}}$ respectively (Figures 4 and 5); iii. the LHV increase in the last 2 weeks didn't exceed 15\%; on the contrary in the first 2 weeks it reached $27 \%$ (Figure 6); iv. $\mathrm{NH}_{3}$ dynamics (Figure 7) shows a potential emission factor into the atmosphere of about $200 \mathrm{mg} / \mathrm{kgGM}$ during the whole period; taking into account that the specific flow rate resulted about $10 \mathrm{Nm}^{3} / \mathrm{kgGM}$, a potential average concentration could be around 20 $\mathrm{mg} / \mathrm{Nm}^{3}$. This value make it necessary a treatment of the process air. v. Cu content (Table 2) of the bio-dried exhausted GM resulted moderate, in agreement with the content of the orig-

Table 1. Elemental composition of initial exhausted grape marc (\%TS and \% VS).

\begin{tabular}{lcccccc} 
& Carbon & Hydrogen & Oxygen & Nitrogen & Sulfur & Ash \\
\% of TS & 54.94 & 5.38 & 32.08 & 2.09 & 0.21 & 4.85 \\
\% of VS & 57.74 & 6.13 & 33.72 & 2.20 & 0.22 & - \\
\hline
\end{tabular}

TS, total solids; VS, volatile solids.

Table 2. VS/TS, TS/GM ratios and moisture and copper content.

\begin{tabular}{lcccc} 
& $\mathrm{kg}_{\text {VS }} / \mathrm{kg}_{\text {IS }}$ & $\mathrm{kg}_{\text {IIS }} / \mathrm{kg}_{\text {GM }}$ & $\mathrm{kg}_{\text {HRO }} / \mathrm{kg}_{\text {GM }}$ & $\mathrm{mg}_{\text {OU }} / \mathrm{kg}_{\text {bio-driedGM }}$ \\
Initial exhausted GM & $93.06 \%$ & $34.94 \%$ & $65.06 \%$ & - \\
Bio-dried GM & $81.38 \%$ & $47.08 \%$ & $52.95 \%$ & 130 \\
\hline
\end{tabular}

VS, volatile solids; TS, total solids; GM, grape marc.



Figure 6. Lower heating value dynamics during the bio-drying run.

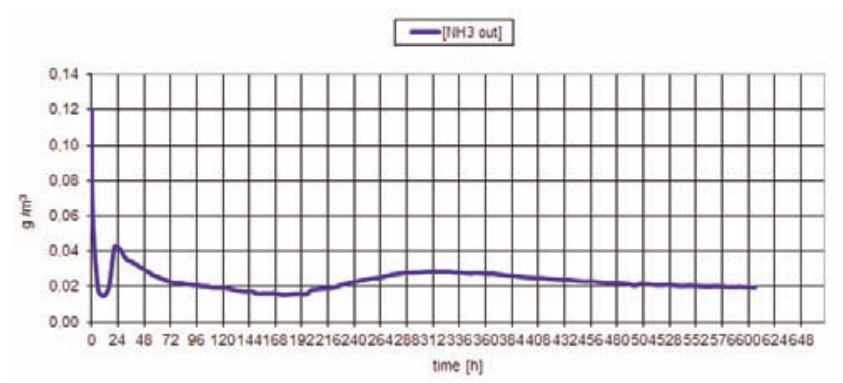

Figure 7. Ammonia dynamics during the bio-drying run. 
inal material pointed out in the literature. ${ }^{14}$ This content is lower than the limit set in the EU for the agriculture use of sludge. ${ }^{15}$ vi. the high concentration of COD in the liquid phase $\left(27.8 \mathrm{~g}_{\mathrm{CoD}} / \mathrm{L}\right)$ can demonstrate that the process of bio-drying is water limited: an addition of water could reactivate the biological activity. ${ }^{16}$ Anyway the final respirometric index value is typical of a good stabilization. Concerning the overall process and the obtained results, the optimal lasting for the exhausted grape marc bio-drying could be around 2 weeks.

The measured data from Tables 1 and 2 and the modeled data from Figure 5 demonstrate that the used model is reliable in terms of water balance: the final moisture was $52.9 \%$ measured versus $53.0 \%$ modeled. The possibility to use the bio-dried material as a SRF for energy proposed was also taken into account in this paper. The top class is expected for $\mathrm{Cl}$ $(<50 \mathrm{mg} / \mathrm{kg})$ and $\mathrm{Hg}(0.022 \mathrm{mg} / \mathrm{kg})$ whilst the final moisture content after bio-drying, being relatively low cannot allow a final LHV typical of the best SRF. This LHV is about 7 $\mathrm{MJ} / \mathrm{kg}_{\text {biodriedGM }}$ after 2 week and respectively 8 $\mathrm{MJ} / \mathrm{kg}_{\text {biodriedGM }}$ after one month. The values are similar to the ones of green wood. Taking into account all these data, the final product is like an SRF:5,1,1 that is similar with the one obtained from the initial exhausted grape marc: SRF: $5,1,1 ;{ }^{17}$ the potential microbial self heating for the final product is very low, and low for the initial exhausted GM. Both SRFslike can be used in a cement factory, but the SRF from bio-drying can be easily stored as its stability is decreased thanks to the moisture limiting content. ${ }^{18}$

\section{References}

1. ISTAT [Internet]. Roma: The Italian National Institute for Statistics. Available from http://www.istat.it/it/

2. Devesa-Rey R, Vecino X, Varela-Alende JL, et al. Valorization of winery waste vs. the costs of not recycling. Waste Manag 2011;31:2327-35.

3. Fiori L, Florio L. Gasification and combustion of grape marc: comparison among different scenarios. Waste Biomass Valor 2010;2:191-200.

4. Thorngate JH, Singleton VL. Localization of procyanidins in grape seeds. Am. J. Enol Vitic 1994;45:259-62.

5. Karleskind A. Sources et monographies des principaux corps gras. In: Karleskind A (ed). Manuel des Corps Gras. Paris: Lavoisier; 1992. pp. 140-144.

6. Maugenet J. Evaluation of the by-products of wine distilleries. II. Possibility of recovery of proteins in the vinasse of wine distilleries. CR Seances Acad Agric Fr 1973;59:481-7.

7. UNI/TS 11184: 2006 Waste and refuse derived fuels - Determination of biological stability by dynamic respirometric index, ICS: [13.030.01] [75.160.10], October 2006.

8. CEN/TR 15590:2007 Determination of potential rate of microbial self heating using the real dynamic respiration index, ICS: [75.160.10], October 2007.

9. Rada EC, Franzinelli A, Taiss M, et al. Lower Heating Value dynamics during municipal solid waste bio-drying. Environ Technol 2007;28:463-69.

10. Ragazzi M, Rada EC, Antolini D. Material and energy recovery in integrated waste management systems: An innovative approach for the characterization of the gaseous emissions from residual MSW bio-drying. Waste Manag 2011;31:2085-91.

11. Rada EC, Venturi M, Ragazzi M, et al. Biodrying role in changeable scenarios of Romanian MSW management. Waste Biomass Valor 2010;1:271-9.

12. Andreottola G, Dallago L, Ragazzi M. Dynamic respirometric tests for assessing the biological activity of waste, Proceedings of the Tenth International Waste Management and Landfill Symposium; 2005 0ct. 3-7; S. Margherita di Pula (CA), Italy.

13. Ciuta MS, Marculescu C, Dinca C, Badea A. Primary characterization of wine making and oil refining industry wastes. Sci B Electr Eng 2011;73:307-20.

14. La Pera L, Dugon G, Rando R, et al. Statistical study of the influence of fungicide treatments (mancozeb, zoxamide and copper oxychloride) on heavy metal concentrations in Sicilian red wine. Food Addit Contam 2008;25:302-12.

15. 86/278/EEC:1998 Council Directive of on the protection of the environment, and in particular of the soil, when sewage sludge is used in agriculture, 12 June 1986.

16. Rada EC, Ragazzi M, Panaitescu V, Apostol T. Bio-drying or bio-stabilization process? Sci B Electr Eng 2005;67:51-60.

17. UNI 9903-1:2004. Non mineral refuse derived fuels - Specifications and classification, ICS: [75.160.10], March 2004.

18. UNI CEN/TR 15508:2008. Key properties on solid recovered fuels to be used for establishing a classification system, ICS: [75.160.10], October 2006. 